\title{
Paradojas y desafíos del patrimonio audiovisual televisivo. Tres casos de estudio del Archivo Histórico de RTA
}

\author{
Paradoxes and challenges of audiovisual heritage of television. Three cases of the \\ Archivo Histórico de RTA
}

\author{
Elina Adduci Spina \\ veolamusica@gmail.com \\ Instituto de Artes del Espectáculo, Facultad de \\ Filosofía y Letras, Universidad de Buenos Aires / \\ Archivo Histórico de Radio y Televisión Argentina S.E, \\ Argentina
}

Recepción: 04 Junio 2019

Aprobación: 13 Abril 2020

Publicación: 01 Marzo 202

Cita sugerida: Adduci Spina, E. (2021). Paradojas y desafíos del patrimonio audiovisual televisivo. Tres casos de estudio del Archivo Histórico de RTA. Sociohistórica, 47, e122. https://doi.org/10.24215/18521606e122
Resumen: El presente trabajo aborda el análisis de las paradojas y los desafíos que supone la patrimonialización de los archivos de televisión, tomando como eje la experiencia del Archivo Histórico de Radio y Televisión Argentina. En primer lugar, se estudian las singularidades del medio televisivo en tanto tecnología cultural (Williams, 2001) y discurso (González Requena, 1995), las vicisitudes históricas de su praxis archivística, las contradicciones inherentes de un proceso de patrimonialización que lo convierte en un patrimonio incómodo (Prats, 1997; Reventós Gil de Biedma, 2007) y el abanico de posibilidades que implica su refuncionalización como patrimonio zombie (Hernàndez i Martí, 2008). En segunda instancia, se hace un breve recorrido por la historia de los archivos televisivos de la Argentina, poniendo especial atención en la reciente creación del Archivo Histórico de RTA. Finalmente, se examinan tres casos de estudio de esta institución con el propósito de observar la multiplicidad de modos en los que dichas paradojas y desafíos se ponen en juego. De allí puede desprenderse que, cuando hacia finales del siglo XX una convergencia de demandas económicas, estatales y sociales comenzó a poner foco en el valor cultural de la televisión, las políticas patrimoniales se toparon con una serie de vicisitudes que, a grandes rasgos, se sintetizaron en las contradicciones que conlleva la archivística audiovisual en tanto práctica arqueológica, la incomodidad que supone la revalorización de contenidos históricamente denigrados y su refuncionalización en un contexto extrañado del original.

Palabras clave: Patrimonio audiovisual, Archivo audiovisual, Televisión, Archivo Histórico de RTA, Medios públicos.

Abstract: This work deals with the analysis of the paradoxes and the challenges that the patrimonialization of the television archives supposes, taking as axis the experience of the Archivo Histórico de Radio y Televisión Argentina. In the first place, the singularities of the television medium as both cultural technology (Williams, 2001) and discourse (González Requena, 1995), the historical vicissitudes of its archival practice, the inherent contradictions of a patrimonialization process that makes it a uncomfortable heritage (Prats, 1997; Reventós Gil de Biedma, 2007), and the range of possibilities implied by its re-functionalization as a zombie heritage (Hernàndez i Martí, 2008) are studied. In the second instance, a brief tour of the history of television archives in Argentina is made, paying special attention to the recent creation of the Archivo Histórico de RTA. Finally, three case studies of this institution are examined 
with the purpose of observing the multiplicity of ways in which these paradoxes and challenges are put into play. From this it can be inferred that when, towards the end of the 20th century, a convergence of economic, state and social demands began to focus on the cultural value of television, patrimonial policies encountered a series of vicissitudes that, in broad terms, were synthesized in the contradictions that the audiovisual archive implies as an archaeological practice, the discomfort that the revaluation of historically denigrated contents supposes and the re-functionalization of them in a strange context of the original.

Keywords: Audiovisual heritage, Audiovisual archive, Television, Archivo Histórico de RTA, Public media.

\section{CONSIDERACIONES PRELIMINARES}

Históricamente, el patrimonio cultural ha sido identificado con aquellos bienes que recuperan, mantienen y transmiten una herencia que marca el signo identitario de un pueblo, de una región o de la humanidad. Este concepto -que a primera vista parecería dar cuenta de una serie de caracteres intrínsecos, neutros y homogéneos- es en realidad la construcción social, cultural e histórica de un consenso edificado sobre un terreno de disputas o, al menos, de tensiones. En este sentido, el proceso de patrimonialización de un bien cultural representa el juicio emitido por una institución hegemónica que mediante el ejercicio de una memoria selectiva intenta establecer una continuidad con el pasado en pos de la legitimación histórica del presente. En esta dinámica, de manera inexorable se abre un campo de batalla que pone de manifiesto tanto la puja de aquellas expresiones que buscan ascender al "olimpo de la cultura", como la lucha de poder entre diversos actores de la sociedad que reclaman voz y voto en la toma de decisiones. Estos acuerdos y desacuerdos tienen lugar en un entorno que está en continua transformación. En consecuencia, lo patrimonial se define como un rasgo netamente coyuntural: lo que hoy no es considerado patrimonio es susceptible de serlo algún día y, por qué no, viceversa. Al respecto, Néstor García Canclini (1999) señala que en las últimas décadas del siglo XX la noción de patrimonio cultural experimentó un triple movimiento de redefinición al contemplar los bienes del pasado junto a los del presente; al tender un puente entre la herencia y las necesidades contemporáneas; y al reconocer tanto la producción de la clase hegemónica como la de la cultura popular. En esta suerte de democratización del patrimonio cultural, una serie de disciplinas fueron rescatadas del ostracismo y legitimadas como auténticos exponentes de la cultura con mayúscula.

En la era de la imagen y de la comunicación, la supremacía del monumento arquitectónico, del arte pictórico y del documento escrito gradualmente comenzó a ceder espacio a nuevas manifestaciones culturales. De este modo, la imagen en movimiento, más precisamente el cine, fue una de las primeras expresiones que buscó ser reconocida en cuanto a su condición artística y a su capacidad de reflejar y de problematizar distintos rasgos de la sociedad. Si bien a partir de la década de 1930 la Federación Internacional de Archivos Fílmicos (FIAF) logró institucionalizar la preocupación de diversas filmotecas y coleccionistas del mundo que abogaban por el incierto destino de las obras y de los soportes cinematográficos, no fue hasta el año 1980, con la Recomendación sobre la salvaguardia y la conservación de las imágenes en movimiento de la UNESCO, que una entidad externa al campo del cine reconoció a nivel mundial el carácter patrimonial de este tipo de documentos. Transitado casi un cuarto del siglo XXI, en la actualidad parecería existir cierto consenso acerca del valor patrimonial de las imágenes en movimiento. Sin embargo, el constante foco puesto sobre la cinematografía ha eclipsado otras manifestaciones del audiovisual, como por ejemplo la televisión.

Desde sus orígenes, la televisión ha sido objeto del menosprecio de los sectores legitimadores de la cultura por ser considerada un medio de comunicación de masas subordinado a los intereses del mercado y/o de 
los diversos gobiernos de turno. Esta situación, sumada a la complejidad tecnológica, operativa o económica que conlleva archivar el flujo televisivo, trajo como resultado que la mayor parte de sus contenidos se hayan perdido para siempre en el "aquí y ahora" de la transmisión. Pero más allá de las apreciaciones negativas y de la poca conciencia por su preservación, lo cierto es que desde siempre la televisión ha estado en el centro de debates que -desde distintas perspectivas- no han hecho otra cosa más que identificar su profundo vínculo con la vida cotidiana. En este sentido, los últimos años fueron escenario de una convergencia de demandas de índole social, económica y estatal que trajeron como resultado un paulatino reconocimiento del medio en tanto patrimonio. Pero eso sí: como un patrimonio incómodo cuya refuncionalización en un contexto extrañado del pasado supone múltiples retos.

Toda esta serie de transformaciones experimentadas a lo largo y a lo ancho del mundo tuvieron resonancia en la Argentina. No obstante, dicha repercusión se expresó en un débil eco que históricamente se tradujo en la enorme deuda que el país posee en materia de preservación audiovisual. Sin la ejecución de políticas de Estado en continuidad y con la postergada puesta en funcionamiento de la Cinemateca y Archivo de la Imagen Nacional (CINAIN), en la actualidad el patrimonio audiovisual argentino se encuentra en un grave y creciente estado de emergencia. En el caso del medio televisivo la situación es similar ya que la mayor parte de su acervo está desaparecido y el escaso material existente se conserva de manera fragmentaria en los archivos privados de las emisoras o bien diseminado en un puñado de organismos públicos y/o colecciones privadas.

En medio de este contexto desfavorable, en el año 2013 se produjo un hito en la historia de los medios de comunicación y del patrimonio audiovisual argentino. Mediante el Decreto 378/2013, la presidenta Cristina Fernández de Kirchner creó el Archivo Histórico de los Servicios de Radiodifusión Sonora y Televisiva del Estado Nacional (Archivo Histórico de RTA), un organismo dependiente de Radio y Televisión Argentina S.E. (RTA) cuyo objetivo principal es la preservación del acervo audiovisual y sonoro de emisoras como Canal 7 - Televisión Pública y Radio Nacional, entre otras. De esta manera, por primera vez en la Argentina se concretó un proyecto institucional decidido a otorgar interés cultural y a preservar la memoria de los medios de comunicación del Estado. Ahora bien, la conquista de este territorio prácticamente inexplorado supone una diversidad de paradojas y de desafíos a resolver. Cómo archivar la dinámica de un flujo, cómo recuperar los contenidos que ya no están, cómo reconstruir el contexto de producción y de recepción de un medio en extinción, cómo legitimar el presente mediante vestigios de un pasado que puede resultar inconveniente o cómo lograr la persistencia de un proyecto estatal en la sucesión de gobiernos de distinto signo político son algunas de las principales preguntas que demandan al menos ser formuladas.

En las siguientes páginas analizaremos las paradojas y los desafíos que supone la patrimonialización de los archivos de televisión centrándonos en la experiencia del Archivo Histórico de RTA. En el primer apartado estudiaremos las singularidades del medio televisivo en tanto tecnología cultural, las vicisitudes históricas de su praxis archivística, las contradicciones inherentes a su proceso de patrimonialización y el abanico de posibilidades que implica su refuncionalización. En el segundo apartado haremos un breve recorrido por la historia de los archivos televisivos de la Argentina poniendo especial atención en la reciente creación del Archivo Histórico de RTA. En el tercer apartado examinaremos tres casos de estudio de esta institución con el objetivo de observar la multiplicidad de modos en los que dichas paradojas y desafíos se ponen en juego.

\section{LA TELEVISIÓN, EL ARCHIVO TELEVISIVO Y EL PROCESO DE PATRIMONIALIZACIÓN}

Como hemos visto, el patrimonio cultural se caracteriza por su poder de condensar en el presente la herencia del pasado y el legado del futuro. En consecuencia, la reflexión sobre el patrimonio televisivo exige un movimiento de "atrás para adelante" capaz de identificar la singularidad tecnológica y cultural del medio, las necesidades y posibilidades históricas de su salvaguarda, las implicancias del proceso de patrimonialización y los mecanismos de (re)interpretación en un contexto atravesado por las nuevas tecnologías. 
Desde el primer experimento presentado por el ingeniero John Logie Baird en 1925, pasando por el establecimiento de las grandes emisoras estadounidenses y europeas en la década de 1940, hasta llegar a la lógica posmoderna del streaming, la televisión ha sido una fuente inagotable de grandes controversias. A partir de su constitución como medio de comunicación de masas, una multiplicidad de enfoques han intentado desentrañar el potente poder que éste ejerce sobre el conjunto de la sociedad. En sus orígenes, el campo de estudio sobre televisión se dividió de manera dicotómica entre la postura del determinismo tecnológico y de la tecnología sintomática. Si la primera perspectiva considera que la tecnología funciona como una esfera autónoma cuyo desarrollo interno marca la agenda de las transformaciones sociales, la segunda plantea que el progreso tecnológico es el síntoma de los procesos de cambio puestos en marcha de manera autosuficiente por la sociedad. De esta manera, tecnología y sociedad serían compartimentos estancos cuya relación se establecería de manera unidireccional. Sin embargo, desde los estudios culturales se gestó una suerte de tercera posición que plantea que los diversos componentes del fenómeno televisivo se relacionan de manera recíproca. Al respecto, Raymond Williams (2011) señala que la televisión es una tecnología cultural particular propia de la sociedad moderna de posguerra. Según el teórico, la acumulación de capital y la innovación técnica transformaron la producción industrial y las formas sociales, lo que dio lugar a nuevas posibilidades y necesidades que se expresaron, por ejemplo, en los medios de comunicación masiva. En el contexto de un nuevo tipo de sociedad expandida, móvil y compleja, la televisión emergió simultáneamente como una tecnología de broadcasting y como un producto netamente comercial. Así, las instituciones de la televisión -ya sea empresas comerciales o el propio Estado- utilizaron al medio como un instrumento para centralizar y difundir de modo amplio mensajes dirigidos a una multiplicidad de hogares, y como un vehículo para promover bienes de consumo y un estilo de vida acorde a las exigencias de la lógica capitalista. En relación con este último aspecto, la demanda de dispositivos fue impuesta por los mecanismos del mercado y el medio propiamente dicho precedió a los contenidos, que no fueron otra cosa que el reciclaje de formas de consumo social ya existentes. ${ }^{1}$ A hora bien, la organización y la experiencia de estas formas nuevas y mixtas experimentaron una radical transformación, ya que la televisión significó un salto de la "secuencia como programación" a la "frecuencia como flujo". En palabras de Williams, "lo que se ofrece no es un programa de unidades separadas con inserciones particulares, sino un flujo planificado, en el cual la serie verdadera no es la secuencia publicada en el horario de programación sino esta secuencia transformada por la inclusión de otro tipo de secuencia, de modo tal que esas secuencias de unidades componen el flujo real" (2001, p. 120). De esta manera, la publicidad, los avances de la programación o los segmentos de continuidad de las emisoras - por citar algunos ejemplos- no son interrupciones sino unidades que se relacionan con las unidades de los programas en un flujo que es planificado tanto en sí mismo como en la fase previa de toda producción televisiva. Desde el punto de vista semiótico, Jesús González Requena (1995) elabora una teoría similar a la de Williams, en la cual el concepto de flujo es reemplazado por el de programación en tanto macrodiscurso televisivo. En este sentido, la particularidad de la televisión -entendida como sistema semióticoradicaría en su cualidad pansincrética de integrar una multiplicidad de discursos que, lejos de ser autónomos, actúan como fragmentos subordinados al discurso global de la programación. Para lograr que las exigencias del texto parcial sean desplazadas a la de la estructura general, el autor sostiene que el macro-discurso de la programación somete a las unidades que contiene a la lógica de la fragmentación, la indefinición de los límites y la continuidad.

La extrapolación de estas teorías televisivas al campo archivístico genera un problema de índole operativo y teórico porque ¿cómo se archiva el flujo o la programación en su conjunto? Históricamente, los archivos de televisión se han caracterizado por adoptar una lógica que tiende a la fragmentación. Así, la materialidad del documento que se conserva parecería actuar como la pieza de un rompecabezas que se encuentra más cerca de reconstruir la integridad de una sub-unidad que la dinámica del flujo o del discurso global que la contiene. En este proceso de descontextualización, en los archivos televisivos es habitual encontrarse con los siguientes casos: 
- Las emisiones de los programas no suelen ser guardadas enteras ya que en la mayoría de los casos se les extrae la tanda publicitaria. Además, cuando se trata de un archivo histórico, rara vez se conservan todas las emisiones de un mismo ciclo.

- En muchas ocasiones sólo se archivan fragmentos de un programa cuyo recorte suele seguir un criterio de tipo temático. Esta práctica resulta habitual en los archivos de noticias, en los que se estila conservar la nota periodística descontextualizada de la/s emisión/es en la/s que fue/ron incluida/s.

- Las publicidades y los segmentos de continuidad son archivados como entidades autónomas.

- El material "en crudo" o "auxiliar" aparece en los archivos como una figura liminal que representa una instancia previa al flujo.

De alguna manera, la lógica fragmentaria del archivo televisivo se debe a que la televisión no nació con la exigencia de ser un "bien archivable" y a que la historia de su conservación se vio atravesada por cuestiones conceptuales, operativas y/o económicas. A nivel mundial, los primeros años de la televisión se perdieron en el "aquí y ahora" de una única transmisión debido a que las emisiones se realizaban en vivo. ${ }^{2}$ De aquella época sólo quedan algunos vestigios en material fílmico correspondientes al rodaje de notas periodísticas en exteriores o de aquellos programas que luego serían re-transmitidos en diferido por otras emisoras o repetidoras. No obstante, en el año 1956 la firma AMPEX lanzó al mercado un soporte revolucionario llamado videotape. Además de abaratar los costos y de eliminar los tiempos del revelado, la cinta magnética sacudió el campo audiovisual al introducir la posibilidad de grabar, borrar y regrabar. En este gesto, que contempla el descarte como un elemento central de su actividad, la industria televisiva demostró su falta de interés por la conservación global de sus productos. De esta manera, el escaso porcentaje de material que sobrevivió hasta nuestros días pertenece en mayor parte a los archivos internos y operativos de las emisoras. ${ }^{3}$ Es decir, acervos conformados a partir de una selección de documentos que fueron conservados con el objetivo de la re-emisión o de la reutilización futura como insumo para la producción de nuevos contenidos para la pantalla. En consecuencia, el concepto originario de "archivo televisivo" respondió más a los requerimientos de la industria que a una demanda de índole patrimonial.

A partir de la década de $1980,{ }^{4}$ la televisión experimentó un paulatino proceso de transformación ya que su reconocimiento en tanto bien cultural y patrimonial trajo como resultado la trascendencia de los límites de su propia esfera. Tal como plantea Gil Manuel Hernàndez i Martí (2010), la patrimonialización implica una construcción social en la que "la tradición aparece como un dispositivo discursivo (convención retóricoideológica) al servicio de las definiciones sociales de la identidad, del ejercicio del poder o de los mecanismos de mercado" (2010, pp.4-5). De esta manera, con la necesidad de integrar su "sombra histórica", las instituciones legitimadoras de la cultura accionan operaciones de olvido y de selección en pos de la construcción colectiva de la memoria. Es decir, se rescatan aquellos referentes que se muestran apropiados para el proyecto del presente, al mismo tiempo que se dejan a un lado aquellos otros cuya activación resultaría inconveniente. Si bien desde sus orígenes la televisión ha actuado como una tecnología cultural que ha tenido un gran impacto sobre la sociedad, durante años ha permanecido en la sombra por ser catalogada de modo despectivo como un fenómeno de masas y/o como un medio de comunicación menor orientado a producir y reproducir mensajes afines a los intereses del mercado o de los gobiernos de turno. En consecuencia, la reciente puesta en valor de la televisión ha implicado una suerte de ascensión hacia la luz que identifica al medio como un patrimonio incómodo. Al respecto, Llorenç Prats (1997) y Ana Reventós Gil de Biedma (2007) plantean que el concepto de patrimonio incómodo se asocia con aquellas expresiones que, si bien no se les puede negar su legitimación simbólica, nadie quiere ni sabe qué hacer con ellas. En este sentido, el desfasaje estético y/o la portación de discursos políticamente incorrectos, propios de los contenidos televisivos del pasado, suelen generar una fuerte tensión con el constructo sociocultural del presente.

Como hemos visto, la patrimonialización de la televisión significa una gran apuesta que implica tanto una práctica arqueológica como una compleja operación de legitimación. No obstante, el intento por preservar la 
lógica de una tecnología que hoy resulta obsoleta representa un desafío aún mayor. La metamorfosis expresada en el salto tecnológico del analógico al digital transformó los mecanismos de producción y de recepción televisiva de una manera tan radical que la refuncionalización de fragmentos del pasado en el contexto del presente trae como resultado un fenómeno de hibridación. Hernàndez i Martí (2008) señala que en el siglo XXI el patrimonio cultural ha experimentado un cambio esencial, dado por su progresiva globalización y por la expansión de sus contenidos. De este modo, el bien patrimonial sufre una desterritorialización que lo posiciona en un limbo entre la tradición y la cultura actual. Para metaforizar esta característica tan singular, el autor utiliza el concepto de zombi patrimonial. En tanto zombi, el patrimonio televisivo vive una vida artificial que recrea, clona o resucita pasajes de su historia a partir de una reformulación orientada por las necesidades y las ansiedades de la sociedad actual. De esta manera, el desarrollo de las nuevas tecnologías le otorga al patrimonio televisivo la potencialidad de mutar en todos los sentidos posibles: mudar de soporte, fragmentar su flujo, reconvertir y multiplicar los contextos de enunciación y así resemantizarse, trascender los límites de la pantalla televisiva y subvertir la lógica del broadcast por la del streaming.

\section{Los archivos televisivos en Argentina y la CReación del Archivo Histórico de RTA}

$\mathrm{Al}$ igual que lo que ocurrió en el resto del mundo, la televisión argentina no nació con una vocación por la preservación ni mucho menos con una conciencia patrimonial. Además, la atención focalizada en la generación de nuevos contenidos para la pantalla, la naturaleza de las primeras transmisiones en vivo y la posterior introducción del videotape trajeron como resultado que la práctica archivística del medio televisivo se torne una tarea un tanto innecesaria, técnicamente compleja y económicamente costosa. En este sentido, la historia de la televisión nacional se encuentra atravesada por la ausencia. Una ausencia que, si bien hoy nos resuena como falta, a lo largo de todo este tiempo se ha expresado como una condición inherente a la lógica de la propia industria televisiva.

A lo largo de casi setenta años de historia la mayor parte de las unidades del flujo televisivo se fueron perdiendo. Si durante los primeros diez años prácticamente no se realizó ningún registro debido a la preponderancia de las transmisiones en vivo, la llegada del videotape no necesariamente se tradujo en un almacenamiento masivo de las emisiones. Un breve repaso por la historia de la televisión evidencia que, en cierta medida, el desarrollo tecnológico fue en detrimento de la praxis archivística y que el registro y acopio de material respondió a las demandas del medio y no a un interés por la salvaguarda.

Tras un período de experimentación, ${ }^{5}$ el 17 de octubre de 1951 se realizó en la Argentina la primera transmisión oficial de televisión. En dicha ocasión, LR3 TV ${ }^{6}$ (Canal 7) fue la emisora encargada de televisar los festejos celebrados en Plaza de Mayo a propósito de una nueva conmemoración del Día de la Lealtad. De este hito de la historia contemporánea no hay registros audiovisuales, ya que la emisión se efectuó mediante tres cámaras de televisión que in situ transmitieron los hechos en directo. En lo que respecta a los años posteriores la situación se vuelve similar, ya que la gran mayoría de los programas y de las publicidades que integraron la acotada franja horaria de la programación de Canal 7 se realizaron en vivo. En aquella época sólo se registraron algunas notas periodísticas que fueron rodadas en cinta fílmica de $16 \mathrm{~mm}$. Posteriormente, los años sesenta revolucionaron el concepto de televisión conocido hasta el momento. La creación de nuevos canales privados, la llegada de la televisión al interior del país y la utilización del videotape marcaron un cambio sustancial en el desarrollo del medio, que tuvo repercusión tanto en el registro como en la posterior guarda o descarte de los contenidos televisivos. A partir de un decreto ${ }^{7}$ firmado por el presidente de facto Pedro Eugenio Aramburu en el año 1958, en el ámbito de la Ciudad de Buenos Aires se fundaron Canal 9 (1960), Canal 13 (1960) y Canal 11 (1961). La aparición de estos tres canales multiplicó de manera considerable los contenidos televisivos aunque, a decir verdad, un importante porcentaje de la programación de aquel entonces estuvo destinado a la emisión de series importadas desde los Estados Unidos. Por otra parte, la 
llegada de la televisión a las provincias supuso dos escenarios: la creación de repetidoras y el nacimiento de nuevos canales. Por un lado, a partir de diciembre de 1960, la utilización del cable coaxil y del radioenlace permitió que la señal de Canal 7 fuera recibida en ciudades como Rosario, Cañada de Gómez, Mar del Plata, Luján, Chivilcoy, Santa Fe y Paraná. Por otro, el surgimiento de nuevas emisoras como Canal 12 de Córdoba (1960), Canal 8 de Mar del Plata (1960), Canal 7 de Mendoza (1961) y Canal 4 de Rosario (1964), entre otras, significó la producción de nuevos programas locales. Por último, en el año 1960, la aparición del videotape cambió los modos de producción televisiva. ${ }^{8}$ A diferencia de lo que ocurría con el fílmico, este invento posibilitó el registro de la imagen en movimiento en una cinta magnética reutilizable. Pero en un contexto de desinterés patrimonial y crisis presupuestaria, en nuestro país el videotape fue concebido más como un herramienta para el registro y la emisión que como un soporte de guarda permanente. ${ }^{9}$ Las décadas de los setenta y los ochenta fueron años de modernización tecnológica, estatizaciones, re-privatizaciones, mudanzas y algunos incendios. Todos estos movimientos hicieron mella en los archivos televisivos, lo que dejó una enorme deuda con el patrimonio audiovisual argentino.

Por todo lo dicho, un alto porcentaje de los contenidos de la televisión nacional se encuentra desaparecido, ya sea porque se borró, se tiró, se vendió, se perdió, se deterioró o no se capturó. No obstante, en Argentina existe una serie de archivos televisivos que se podrían clasificar en dos grandes categorías: los archivos operativos de los canales, conformados a partir de las necesidades de las emisoras, y los archivos particulares, creados de manera intuitiva por coleccionistas o espectadores aficionados que fueron grabando del aire distintos contenidos según un interés particular. A partir de la década de 1990, la industria televisiva comenzó a poner el foco en el material de archivo, ya que éste representaba una potente fuente de experiencia emocional así como también un insumo barato para la creación de nuevas producciones. Así, en el año 1994, Arte Radiotelevisivo Argentino (ARTEAR) fundó Volver, una señal de cable creada para re-emitir los envíos históricos de la empresa; y Raúl Portal lanzó Perdona Nuestros Pecados, un ciclo que marcó el inicio del boom del género de los "programas archivo". En la actualidad, el auge de internet y de los sistemas de video on demand revolucionó el concepto tradicional de televisión y provocó un fortalecimiento de los archivos. Por un lado, desde el sector industrial los canales se inscriben en la creciente tendencia de archivar y migrar sus contenidos a plataformas como YouTube, Netflix, Cablevisión Flow, Bacua, Odeón/Cine Ar Play, Contar o Movistar Play, por citar algunas de ellas. Por otro, desde la sociedad civil son cada vez más los coleccionistas que deciden compartir sus archivos registrados de manera particular en páginas web, redes sociales y sitios de alojamiento de videos.

$\mathrm{Al}$ margen de este tipo de emprendimientos que tienen como meta principal la facilitación del acceso ya sea gratuito, pago o monetizado-, en el país escasean proyectos orientados a la preservación. La dificultad por establecer políticas públicas en continuidad y la tan postergada puesta en funcionamiento de la CINAIN han generado una verdadera crisis en el seno de la memoria audiovisual nacional. Si bien existe una serie de organismos estatales que tienen en guarda material televisivo, el Centro de Conservación y Documentación Audiovisual (CDA) de Córdoba fue la primera institución pública concebida con la necesidad específica de salvaguardar archivos de televisión. Creada en 1994 y reglamentada en 2002, esta entidad -dependiente de la Universidad Nacional de Córdoba- ${ }^{10}$ nació con el objetivo de recuperar y resguardar el archivo fílmico del noticiero de Canal 10 del período 1962-1980, perteneciente a los Servicios de Radio y Televisión de dicha universidad. Luego del inicio de esta primera experiencia, el país tuvo que aguardar poco más de dos décadas por la concreción de un proyecto de carácter integral, federal y nacional, como lo es el Archivo Histórico de RTA.

Si bien en Canal 7 y Radio Nacional hubo una serie de iniciativas orientadas a la salvaguarda del material, la gestión de Tristán Bauer ${ }^{11}$ fue fundamental para sentar las bases de lo que luego sería el Archivo Histórico de RTA. Durante su mandato se construyeron dos bodegas de guarda ${ }^{12}$ acondicionadas a partir de un protocolo de convivencia de formatos heterogéneos, se adquirió un equipo para transferir material fílmico de 35 y 16 
$\mathrm{mm}$, y se elaboró un documento de trabajo para la preservación digital de material audiovisual histórico en soporte fílmico y magnético. Como resultado de este proceso, el 9 de abril de 2013 el Archivo Histórico de RTA fue institucionalizado ${ }^{13}$ mediante el Decreto del Poder Ejecutivo $N^{\circ} 378 / 2013$, firmado por la presidenta Cristina Fernández de Kirchner. En su reglamento de funcionamiento plantea como objetivo principal la administración, conservación y puesta en estado público de los registros sonoros, documentales, videográficos y cinematográficos grabados, emitidos y existentes en las dependencias de RTA. Además, indica que todos esos registros son pasibles de ser declarados de valor histórico y cultural, según los alcances que establece el artículo 138 de la Ley de Servicios de Comunicación Audiovisual. En este sentido, por primera vez en la historia de la Argentina, el Estado asumió la responsabilidad de preservar los medios de comunicación públicos desde una perspectiva patrimonial.

El heterogéneo acervo del Archivo Histórico de RTA recorre la historia de la industria del broadcasting en Argentina a cargo del Estado nacional. Conserva registros sonoros de Radio Nacional y piezas audiovisuales de Canal 7. Por cuestiones operativas, el archivo televisivo se encuentra dividido en el Archivo de Noticias y el Archivo de Artística. En el primero se custodian notas periodísticas que datan desde mediados de la década de 1950, y en el segundo se documenta material con fecha posterior al año 1978, debido a que en la mudanza del viejo Canal 7 al edificio de ATC las autoridades militares decidieron realizar un descarte masivo. Sus fondos, secciones y colecciones se componen de los más variados formatos analógicos y digitales: fílmico de $16 \mathrm{~mm}$, cinta cuádruplex de 2", cinta de 1" (formato B y C), videocasetes U-matic y Betacam, discos XDCAM y ODA, y cintas LTO, entre otros.

El proyecto inicial del Archivo Histórico de RTA se apoyó en tres pilares fundamentales: la conservación, la catalogación y el acceso. De esta manera, se almacenó el material en las dos bodegas de guarda, se diseñó un sistema de catalogación acorde a las características específicas de los materiales y se creó la página web Archivo Prisma. En su corta existencia, ${ }^{14}$ Prisma funcionó como un archivo vivo y de construcción diaria destinado a brindar acceso universal vía internet a los registros sonoros y audiovisuales históricos de RTA. Además, con el objetivo de fortalecer los vínculos interinstitucionales, este sitio también actuó como una vidriera en la que se exhibían archivos de diferente naturaleza, obtenidos a partir de los convenios celebrados entre RTA y otros organismos del Estado.

\section{Tres casos de estudio del Archivo Histórico de RTA}

Como todo archivo de televisión, el Archivo Histórico de RTA es un territorio en el que se entrecruzan ausencias, presencias y potencialidades. Así, el ejercicio de la memoria implica un tránsito por caminos laberínticos colmados de vacíos que no siempre pueden ser suplidos de manera ortodoxa. Debido a su magnitud y heterogeneidad, el examen integral del Archivo Histórico de RTA se torna una tarea de gran dificultad. No obstante, las colecciones Gente (1960), [Promociones oficiales de la dictadura civico-militar] (1979) y Los gringos (1984) resultan operativas para realizar un muestreo de las particularidades de tan vasto acervo. A continuación, nos serviremos de estos tres casos de estudio con el objetivo de analizar cómo el carácter paradojal propio del patrimonio televisivo -expresado en la pérdida del flujo, la singularidad fragmentaria y su carácter incómodo- puede también ser abordado a partir del desafío que demanda su refuncionalización.

\section{Gente (1960)}

Creado y conducido por Augusto Bonardo, Gente fue un programa de entrevistas biográficas cuyo objetivo principal era la difusión del pensamiento de diferentes personalidades de la cultura nacional. El ciclo recorrió más de veinte años de la historia de la televisión argentina, ya que tuvo una primera temporada 
en el año 1960 por Canal 7, una segunda en 1961 por Canal 13 (rebautizado de aquí en adelante como $L a$ gente), una tercera en 1965 otra vez por Canal 7, y una cuarta y última en 1982 por ATC. Cabe destacar que el paso de Augusto Bonardo por Canal 7 ha sido objeto de grandes controversias: por un lado, fue nombrado como director de la emisora tras el golpe de Estado de 1955, y por otro, se vio forzado a levantar su programa en dos oportunidades. ${ }^{15}$

En la primera temporada del año 1960, Gente se emitió los días viernes a las 23:30 horas. El envío no tenía un horario de finalización definido ya que, si la dinámica de la conversación lo ameritaba, la entrevista se prolongaba hasta altas horas de la madrugada. A través de una suerte de culto por el ejercicio de la palabra, el programa hacía especial hincapié en el valor del testimonio oral como fuente de la historia. De esta manera, la reflexión acerca de la identidad socio-cultural del país no era abordada a partir de sus grandes hitos, sino desde la reconstrucción de la memoria de sus "grandes protagonistas". A su vez, la cultura nacional era entendida desde un sentido amplio puesto que los entrevistados podían proceder de las ciencias médicas, como Florencio Escardó; de la política académica, como Risieri Frondizi; del variado arco político, como Alicia Moreau de Justo, José Mazar Barnett o Recaredo Ernesto Vázquez; de la considerada alta cultura, como Cesáreo Bernaldo de Quirós o Silvina Bullrich; o de la cultura popular, como Carlos A. Petit, Fernando Ochoa o los hermanos Expósito, por citar algunos ejemplos.

Por cuestiones técnicas el ciclo se emitió íntegramente en vivo. Recordemos que en la Argentina de los años sesenta el videotape se encontraba en una primera fase de experimentación y el fílmico era reservado para el rodaje de notas sueltas que luego serían incluidas en la emisión. No obstante, algo de lo efímero de aquellos envíos ha sido conservado hasta nuestros días gracias a que Bonardo grabó de manera parcial el audio de una serie de programas. Al comenzar el ciclo, el conductor planteó que Gente exploraría el género biográfico televisivo con el objetivo de crear "apuntes para un tiempo futuro y para una divulgación en el presente" que luego serían enviados al Museo de la Palabra de la Biblioteca Nacional. Y así fue. En la actualidad, el área de Audioteca y Mediateca de la Biblioteca Nacional Mariano Moreno conserva treintaitrés discos sonoros analógicos de pasta que contienen el audio de diecinueve envíos, como también el fragmento de una cena de camaradería conducida por Bonardo -celebrada a propósito del primer aniversario del golpe cívico-militar de 1955- y el pasaje de tres emisiones de Apuntes. A contramano de la lógica operativa imperante en los archivos de televisión, en este gesto por la conservación se advierte una primigenia conciencia de tipo patrimonial. No obstante, dicha valoración fue otorgada al contenido y no al fenómeno televisivo en sí. A lo largo del ciclo Bonardo repetía que, en una comunidad sin memoria, la grabación de las entrevistas pretendía dejar para las generaciones venideras un testimonio de cómo era la sociedad del año 1960. Si bien no sabemos a ciencia cierta por qué el conductor registró el audio y no la imagen en movimiento, lo cierto es que el criterio patrimonial fue aplicado de manera unívoca a la impronta de la palabra, y la televisión quedó relegada como un mero canal o medio de comunicación entre tantos otros.

En el marco de un convenio celebrado con la Biblioteca Nacional, en el año 2018 el Archivo Histórico de RTA repatrió una copia digital de dichos audios. De esta manera, luego de más de cincuenta años, estos materiales volvieron a su lugar de origen para ser refuncionalizados como archivos de televisión. Tras la repatriación, los programas fueron catalogados según criterios internos y las copias de los audios fueron almacenadas en un storage y en un disco ODA. La gestión en ejercicio en aquel entonces alojó en la página web del Archivo Histórico de RTA una serie de fragmentos sonoros de los envíos y determinó que el acceso a los registros completos sólo fuera posible mediante una visita presencial a la oficina del Archivo ubicada en la Televisión Pública. ${ }^{16}$ 


\section{[Promociones oficiales de la dictadura cívico-militar] (1979)}

Como ya hemos visto, las publicidades son una parte esencial de la televisión dado que condicionan tanto la dinámica estructural de los programas y del flujo como también el perfil ideológico de la emisora. Dentro del rubro de la publicidad televisiva podemos encontrar tres grandes categorías: los comerciales de bienes y servicios, los anuncios institucionales del canal y las propagandas políticas y/o estatales. Entre los años 1976 y 1983, la Argentina se encontró bajo el dominio de la dictadura cívico-militar autodenominada Proceso de Reorganización Nacional. En ese contexto, los canales de aire fueron intervenidos por las Fuerzas Armadas y Canal 7 (rebautizado sucesivamente como A78TV y ATC) funcionó como la emisora oficial en la que se concentró la producción y difusión de los mensajes del Estado. ${ }^{17}$ [Promociones oficiales de la dictadura cívicomilitar] es un compendio de once campañas ${ }^{18}$ que, a partir del abordaje de una heterogeneidad de temáticas, funcionaron como un instrumento de propaganda de la dictadura. Fueron producidas por ATC y tuvieron circulación en el resto de los canales del país durante los meses de septiembre, octubre y noviembre de 1979. Cada promoción es antecedida por una placa (que se complementa con una voz en off) en la que se consignan datos técnicos: el número de máquina, rollo y estudio, el título, la fecha del VTR y de aire, y los nombres del operador y del director. Al finalizar, una voz prescribe el cese de una serie de campañas e indica que la información deberá ser remitida a los canales del interior vía Cadena Nacional. Si bien estas publicidades son apreciadas como unidades autónomas que fueron arrancadas de su flujo, el modo en el que fueron archivadas ofrece un testimonio que documenta tanto su contexto como las formas de producción televisiva durante la época dictatorial.

Tras ser conservado durante años en su soporte original de cinta magnética (un cuádruplex de 2" también conocido como VTR), en el 2013 este contenido fue digitalizado y migrado a un disco XDCAM, ${ }^{19}$ y en agosto de 2015 fue difundido a través de la página web y del canal de YouTube de Archivo Prisma. Dado que el material fue publicado sin edición ni restauración alguna, en él se puede observar una multiplicidad de deterioros audiovisuales típicos de la degradación de los soportes fílmicos ${ }^{20}$ y magnéticos, como rayas, flacking off(desprendimiento de emulsión), warping (deformación), cortes, pérdida de color y contraste, etc. En esta decisión, Prisma revelaba uno de los criterios fundamentales de su política editorial: ofrecer un acceso lo más transparente e inalterado posible al acervo, con el objetivo de dar cuenta de la historia del material. De esta manera, las promociones en cuestión fueron refuncionalizadas en varios aspectos. Por un lado, fueron extraídas de su flujo original para ser archivadas como registros autónomos; por otro, fueron rescatadas de la oscuridad de los archivos -lugar al que habían sido confinadas debido tanto a su valor como a la incorrección política de sus mensajes- con el propósito de revitalizarlas como objeto de consumo en múltiples pantallas; y por último, fueron resemantizadas, ya que de meras propagandas de la dictadura cívico-militar se convirtieron en herramientas críticas capaces de reflexionar sobre ella.

\section{Los gringos (1984)}

Los gringos fue una miniserie de ficción que se emitió por la pantalla de ATC los miércoles a las 22 horas entre los meses de julio y noviembre del año 1984. Bajo la dirección de David Stivel y con la autoría de Juan Carlos Gené, el ciclo narró la historia de la inmigración en la Argentina de fines del siglo XIX y principios del XX, a partir de un relato focalizado en una serie de familias de origen italiano, español, judío y criollo. A lo largo de sus veinte capítulos, el elenco contó con la participación de destacadas figuras, como Bárbara Mugica, Julio de Grazia, Carlos Carella, Marta Bianchi, Emilio Alfaro, Darío Grandinetti, Miguel Ángel Solá, Luisina Brando, Oscar Martínez, Gabriela Toscano y Osvaldo Terranova, entre otras. El programa reviste un importante valor histórico y artístico por tratarse de una de las primeras ficciones históricas tras la vuelta 
de la democracia, como también por significar el regreso al país de Stivel y Gené, quienes estuvieron exiliados en Colombia y Venezuela, respectivamente, durante la última dictadura cívico-militar.

Tal como se estilaba con los programas de ficción de la época, Los gringos fue grabado en cintas cuádruplex de 2". A diferencia de lo que ocurrió con la mayoría de los ciclos del período, todos los soportes fueron guardados hasta nuestros días. ${ }^{21}$ No obstante, más del $65 \%$ del contenido se encuentra inaccesible debido a que catorce de los veintiún cuádruplex están afectados por el síndrome de glue flange. El glue flange es un fenómeno de degradación causado por la descomposición de un adhesivo que el fabricante $3 \mathrm{M}$ colocaba en el interior del envase de los soportes con el propósito de adherir una fina capa de gomaespuma que protegía y amortiguaba el carrete. Al traspasar las espiras del rollo, el pegamento degradado invade la cinta e imposibilita su reproducción. En consecuencia, archivar un material no significa necesariamente preservarlo. Para ello es necesario que se ejecuten políticas públicas que garanticen la guarda, la conservación y el acceso a los archivos. A falta de una conciencia patrimonial, se estima que el deterioro de esta colección se produjo en el transcurso de las décadas de 1990 y 2000. Tras la creación del Archivo Histórico de RTA, en el año 2015 la institución solicitó asistencia a técnicos del Instituto Nacional de Tecnología Industrial (INTI) y de The Audiovisual Preservation Exchange (APEX) ${ }^{22}$ No obstante, los experimentos de limpieza no han llegado a buen puerto, ya que el pegamento es de difícil remoción y las experiencias de restauración realizadas en otras partes del mundo fueron efectuadas con un compuesto químico que se ha discontinuado en el mercado debido a su alta toxicidad. En el marco de un convenio celebrado con el Archivo Nacional de la Memoria, en la actualidad Mario Norro y Nahuel Tripicchio (integrantes del equipo de conservación de dicha institución) se encuentran en plena etapa de investigación en búsqueda de procedimientos y solventes alternativos para la limpieza.

Entre el año 2018 y 2019 se procedió a digitalizar y a catalogar los siete soportes que no presentaban problemas de conservación, correspondientes a los capítulos 1, 2, 12, 14, 15, 18 y $19 .{ }^{23}$ En consecuencia, hasta no descubrir un método para restaurar el resto de las cintas, el acceso al material se torna fragmentario. Sin embargo, en la empresa por reconstruir esta suerte de rompecabezas surge la oportunidad de ampliar el espectro. El rastreo de nuevas piezas abre la posibilidad de explorar el Fondo de Fotografía Institucional de la Televisión Pública, en el que se conservan veintitrés negativos de $35 \mathrm{~mm}$ con imágenes del rodaje de las emisiones; inspeccionar la infinidad de hemerotecas públicas del país en las que se archivan notas periodísticas y material de prensa del programa; o bien, examinar los guiones de los veinte capítulos mecanografiados y conservados por Juan Carlos Gené, actualmente custodiados por el Instituto de Artes del Espectáculo "Dr. Raúl H. Castagnino”, dependiente de la Facultad de Filosofía y Letras de la Universidad de Buenos Aires. De esta manera, la inaccesibilidad del ciclo en su completitud de alguna manera fuerza la búsqueda, el hallazgo y la puesta en relación de esta serie de paratextos, lo que propicia un abordaje global de lo que fue el fenómeno Los gringos.

\section{REFLEXIONES FINALES}

Desde el punto de vista conceptual y pragmático, el archivo televisivo está íntimamente relacionado con la idea de fragmento. Al seleccionar y extraer unidades del flujo televisivo, la praxis archivística fractura y descontextualiza la enunciación de un discurso en continuidad. Si bien en la actualidad las nuevas tecnologías brindan eficaces herramientas de captura y almacenamiento, lo cierto es que, en un medio en continua interacción, el registro del flujo de una emisora también requeriría del registro del flujo del resto de los canales que emiten en simultáneo y del modo en el que la programación se dispone en las plataformas de streaming. Es decir, el archivamiento del fenómeno completo es una tarea inalcanzable.

Al margen de esta realidad, la televisión no nació como un "bien archivable" ni mucho menos, patrimonializable. Tras un largo período en el que reinó la falta de interés y la complejidad operativa, técnica 
y económica para grabar las emisiones, la invención del videotape introdujo el descarte como un elemento central de la actividad. Además, la creación de los primeros archivos se subordinó a las necesidades operativas de las emisoras. Cuando hacia finales del siglo XX una convergencia de demandas económicas, estatales y sociales comenzó a poner foco en el valor cultural del medio, las políticas patrimoniales se toparon con una serie de vicisitudes que, a grandes rasgos, se sintetizaron en las paradojas y desafíos que conlleva la archivística audiovisual en tanto práctica arqueológica, la incomodidad que supone la revalorización de contenidos históricamente denigrados y su refuncionalización en un contexto extrañado del original.

El Archivo Histórico de RTA se inscribió en esta nueva tradición. Javier Trímboli (2017) reflexiona que su origen estuvo signado por un movimiento contra natura ya que, además de montarse sobre un acervo desbandado, reservado y bajo la dominancia de la pantalla, la difusión de sus registros develó una narrativa quebradiza -y durante años silenciada- construida por el Estado en sus diversas facetas y coyunturas. En este sentido, la edificación de bodegas, el mejoramiento de las condiciones de guarda, la renovación tecnológica y la democratización de los contenidos mediante la página web de Archivo Prisma significaron el primer gran paso hacia la concreción de una tarea relegada durante años. No obstante, Hernàndez I Martí (2010) plantea que la activación patrimonial es una operación subsidiaria del contexto socio-político. Así, un bien cultural puede integrar la sombra patrimonial, emerger a la luz del reconocimiento oficial y luego volver a hundirse en la oscuridad. Algo de esta dinámica se puso en práctica tras el cambio de gobierno acontecido el 10 de diciembre de 2015, ya que de una concepción que alentaba la salvaguarda de "la memoria de un Estado que no le teme a su propia historia" ${ }^{24}$ se pasó a una discursividad que, en palabras de Trímboli, "hace de la sutura de la 'grieta' uno de sus caballitos de batalla” (2017, p. 189). En sus cuatro años de gestión, la administración de la alianza Cambiemos empujó al Archivo Histórico de RTA hacia una situación dramática: el abandono de la bodega de Pacheco trajo como resultado un grave deterioro edilicio y una consecuente degradación de los soportes, que se vieron sometidos a condiciones de temperatura y humedad inadecuadas; el cierre de la web de Archivo Prisma desactivó el acceso irrestricto y el visionado on line de los registros, y el robo de equipamiento en la oficina del área redujo de manera considerable su operatividad. Entonces, en un contexto de retroceso y oscuridad como este, las paradojas y los desafíos a los que hemos hecho referencia parecieran cobrar más fuerza o, mejor dicho, redefinirse. En todo caso, hoy la pregunta a responder es si tenemos que luchar contra los problemas que dañan a los archivos o contra las políticas que generan esos daños.

\section{FUENTES LEGISLATIVAS Y ADMINISTRATIVAS}

APEX (2015). Asesoría del Archivo de Cintas de Video - Canal 7 TV Pública Buenos Aires.

Decreto 1209/2010. Buenos Aires, 30 de agosto de 2010.

Decreto 378/2013. SERVICIOS DE COMUNICACION AUDIOVISUAL. Archivo Histórico de los Servicios de Radiodifusión Sonora y Televisiva del Estado Nacional. Buenos Aires, 9 de abril de 2013.

Federación Internacional de Archivos Fílmicos (2008). Código de ética (3ra Ed.).

Ley 25119/1999. CINEMATECA Y ARCHIVO DE LA IMAGEN NACIONAL. Buenos Aires, $1^{\circ}$ de septiembre de 1999.

Ley 26522. SERVICIOS DE COMUNICACIÓN AUDIOVISUAL. Buenos Aires, 10 de octubre de 2009.

Radio y Televisión Argentina S.E. (2017). Comunicado. Recuperado a partir de: http://www.archivorta. com.ar/wp-content/uploads/2017/12/Comunicado-AHRTA.pdf

Archivo Histórico de RTA (2018). Incorporación al AHRTA de audios inéditos del programa Gente conducido por Augusto Bonardo. Recuperado a partir de: http://www.archivorta.com.ar/incorporacion-al-a hrta-de-audios-ineditos-del-programa-gente-conducido-por-augusto-bonardo/ 


\section{REGLAMENTO DE FUNCIONAMIENTO DEL ARCHIVO HISTÓRICO DE LOS SERVICIOS} DE RADIODIFUSIÓN SONORA Y TELEVISIVA DEL ESTADO NACIONAL. Buenos Aires, 27 de febrero de 2014.

Televisión Pública. Área TIC, Sección Digitalización de Archivos Audiovisuales (2008). Protocolo de Trabajo para la Preservación Digital de Material Audiovisual Histórico.

Televisión Pública (2013). Preservación digital y democratización de los archivos históricos de RTA SE.

UNESCO (1980). Recomendación sobre la salvaguardia y la conservación de las imágenes en movimiento de la UNESCO. Belgrado: Conferencia General - 21a Reunión.

\section{Fuentes AUdiovisuales}

Radio y Televisión Argentina S. E. [ATC] (1979). [Promociones oficiales de la dictadura civico-militar]. Recuperado a partir de: http://www.archivorta.com.ar/asset/promociones-oficiales-de-la-dictadura-civicomilitar-28-09-1979/

Radio y Televisión Argentina S. E. [ATC]. (1984). Los gringos.

Radio y Televisión Argentina S. E. [Canal 7]. (1960). Gente.

Cristina Fernández de Kirchner. (2015). Archivo Prisma, una web del Archivo Histórico de RTA. Recuperado a partir de: https://www.youtube.com/watch?v=y-llheiLBFk

\section{REFERENCIAS}

García Canclini, N. (1999). Los usos sociales del Patrimonio Cultural. En E. Aguilar Criado (Coord.), Patrimonio Etnológico. Nuevas perspectivas de estudio (pp. 16-33). Andalucía: Consejería de Cultura.

González Requena, J. (1995). El discurso televisivo: espectáculo de la posmodernidad. Madrid: Cátedra.

Hernàndez i Martí, G. M. (2008). Un zombi de la modernidad: el patrimonio cultural y sus límites. En La Torre del Virrey: revista de estudios culturales, $\mathrm{N}^{\circ} 5$.

Hernàndez i Martí, G. M. (2010). La memoria oscura. El patrimonio cultural y su sombra. En J. Rivera Blanco (Coord.), VI Congreso Internacional "Restaurar la Memoria": La gestión del patrimonio: hacia un planteamiento sostenible (pp. 629-637). Valladolid: Junta de Castilla y León.

Hidalgo Goyanes, P. (2015). Preservación del Patrimonio Audiovisual de Televisión. El archivo de Televisión Española (TVE): de los orígenes a la digitalización (Tesis Doctoral). Universidad Complutense de Madrid. Facultad de Ciencias de la Información. Departamento de Biblioteconomía y Documentación, Madrid.

Landi, O. (1992). Devórame otra vez. Québizo la televisión con la gente. Quéhace la gente con la televisión. Buenos Aires: Planeta.

López de Solís, I. y Martín López, C. (2011). Nuevas estrategias de negocio y valorización de los archivos audiovisuales en internet. En El profesional de la información, 20(6).

Mindez, L. (2001). Canal Siete. Medio siglo perdido. La historia del Estado argentino y su estación de televisión. Buenos Aires: Ciccus La Crujía.

Monasterio Morales, J. E. (2005). La preservación del patrimonio audiovisual. Funciones de la filmoteca. En PH Boletín del Instituto Andaluz del Patrimonio Histórico, $\mathrm{N}^{\circ} 5$.

Osorio Alarcón, F. (2016). Un modelo para la gestión, organización y administración de las tareas que inciden en el desarrollo de colecciones de imágenes fotográficas y medios audiovisuales. México D.F.: MFA Imaging Arts \& Science.

Prats, L. (1997). Antropología y Patrimonio. Barcelona: Ariel.

Reventós Gil de Biedma, A. (2007). Patrimonios incómodos para la imagen que Barcelona ofrece al mundo. PASOS. Revista de Turismo y Patrimonio Cultural, 5(3). 
Trímboli, J. (2017). Archivo en apremios. En: A. Rodríguez y C. Elizondo (Comps.), Tiempo archivado. Materialidad y espectralidad en el audiovisual (pp. 181-193). Bernal: Universidad Nacional de Quilmes.

Ulanovsky, C., Itkin, S. y Sirvén, P. (1999). Estamos en el aire. Una historia de la televisión en la Argentina. Buenos Aires: Planeta.

Varela, M. (2005). La televisión criolla. Desde sus inicios hasta la llegada del hombre a la Luna 1951-1969. Buenos Aires: Edhasa.

Williams, R. (2011). Televisión. Tecnología y forma cultural. Buenos Aires: Paidós.

\section{Notas}

1 Williams se refiere a formas heredadas de otro tipo de actividad social, como la noticia, la secuencia, las prioridades, la presentación, la visualización, el debate y la discusión, la educación, las obras dramáticas, los filmes, el teatro de variedades, el deporte, la publicidad, y los pasatiempos.

2 Las únicas emisiones que no se transmitían en vivo provenían de los enlatados, concepto que en la jerga televisiva refiere a las películas o a los programas de televisión producidos por otras emisoras.

3 Resulta de importancia aclarar que muchos "archivos operativos" fueron a parar de manera parcial a otras instituciones públicas o privadas. No obstante, la aparición de formatos de grabación casera abrió una nueva arista en materia de archivos televisivos, ya que muchos documentos se encuentran dispersos en manos de coleccionistas o de espectadores aficionados.

4 Este proceso fue impulsado por la creación de la Federación Internacional de Archivos Televisivos (FIAT), en 1977, y por la publicación de la ya mencionada Recomendación sobre la salvaguardia y la conservación de las imágenes en movimiento de la UNESCO, en 1980.

5 En la década de 1930, ingenieros y radioaficionados se encargaron de explorar el nuevo medio y de realizar las primeras transmisiones experimentales en el país. En este primer período se destacan organizaciones como el CAT (Centro Argentino de Televisión) y el IET (Instituto Experimental de Televisión), fundadas en 1931 y 1938, respectivamente.

6 LR3 TV o LR3 Radio Belgrano TV es la denominación de la primera emisora de televisión en la Argentina. Al utilizar la frecuencia del siete, también fue conocida como Canal 7. En sus orígenes se trató de una empresa privada (a cargo de Jaime Yankelevich) que contó con apoyo estatal.

7 Con fecha del 28 de abril de 1958 , el Decreto $N^{\circ} 6287 / 58$ otorgó a empresas privadas las primeras licencias para gestionar canales de televisión.

8 A partir del año 1960, la televisión argentina comenzó a alternar sus emisiones entre programación en vivo y grabada. Debido al alto costo de las nuevas máquinas de grabación, el videotape se introdujo de manera gradual y en sus orígenes estuvo principalmente reservado para las publicidades.

9 En la actualidad, muchos de los programas de la década del sesenta y setenta se conservan en cintas fílmicas, ya que los canales de la capital distribuían sus programas hacia el interior del país a partir del proceso denominado "video to film".

10 En la actualidad, el CDA es una dependencia compartida entre la Facultad de Filosofía y Humanidades y la Facultad de Artes de la Universidad Nacional de Córdoba.

11 Tristán Bauer fue titular del Sistema Nacional de Medios Públicos (2008-2010) y presidente de Radio y Televisión Argentina S.E. (2010-2015).

12 Las bodegas se encuentran emplazadas en las instalaciones de la Televisión Pública (CABA) y en el predio de la planta transmisora de Radio Nacional (Pacheco, provincia de Buenos Aires).

13 El Archivo Histórico de RTA fue reglamentado en el año 2014 y durante el transcurso del 2015 se puso en funcionamiento.

14 La web de Archivo Prisma fue lanzada el 29 de octubre de 2015. En febrero de 2017, tras la renuncia de Javier Trímboli -primer coordinador concursado del área-, el sitio dejó de actualizarse hasta que finalmente fue dado de baja el 29 de noviembre de 2017. La gestión de Eugenia Izquierdo (2017-2020) -segunda coordinadora del área, designada por el directorio de RTA- migró las fichas de catalogación de Prisma a una web denominada Archivo RTA y dio de baja un alto porcentaje de los registros audiovisuales que se podían visualizar on line.

15 En 1960, Gente fue abruptamente levantado del aire debido a diferencias entre Augusto Bonardo y los productores Moisés Guterman y Osvaldo Parrondo. Al año siguiente, Bonardo trasladó el programa a la pantalla de Canal 13 (bajo el nuevo título de La gente) y los productores lanzaron Apuntes, un ciclo de formato similar conducido por Pedro Larralde y emitido por Canal 7. En 1965, el programa corrió con la misma suerte, pero esta vez el levantamiento fue provocado por las presiones de corte macartista ejercidas desde el Frente de Entidades Democráticas Anticomunistas (FAEDA).

16 El catálogo se encuentra disponible en http://www.archivorta.com.ar/programa/gente/ 
17 Durante la dictadura cívico-militar los canales quedaron a cargo de la Secretaría de Información Pública, a excepción de Canal 7, que quedó bajo la órbita de la Secretaría de Comunicaciones, dependiente de Presidencia de la Nación.

18 Las campañas son: Antecedente 2, Armada Submarino, Ejército Autoridad 1, Ejército Autoridad 2, Ejército Autoridad 4, Argentinos de hoy (dos versiones), FENDIM - Semana del deficiente mental, Semana de la Lepra, Simposio Internacional Técnicas de evaluación y minería de uranio, y Armada Escuela de Mecánica.

19 Por cuestiones de compatibilidad operativa con la infraestructura broadcast del canal, el material audiovisual histórico se digitaliza en XDCAM. Para ello, se utiliza el formato de ordenamiento lógico de datos IMX 50, por ser el soporte de Standard Definition con mayor calidad ofrecido por el XDCAM.

20 La textura de la imagen denota que las promociones fueron rodadas en fílmico y que luego fueron transferidas a cinta magnética.

21 Se cree que estas cintas representan la única copia del ciclo.

22 APEX es una iniciativa del programa Moving Image Archiving and Preservation de la New York University.

23 El catálogo se encuentra disponible en http://www.archivorta.com.ar/programa/los-gringos/

24 Cristina Fernández de Kirchner (2015). Archivo Prisma, una web del Archivo Histórico de RTA. Recuperado de: https ://www.youtube.com/watch?v=y-llheiLBFk 